\title{
El Timeo-Critias, una geografia imaginaria entre la escatología y la historia
}

\section{(The Timaeus-Critias, an imaginary geography between escatology and history)}

\author{
Tomás Morales CATURLA
}

Recibido: 13 de diciembre de 2012

Aceptado: 12 de marzo de 2013

\section{Resumen}

La geografía del Timeo-Critias es la etapa final de un proceso a través de diferentes mitos escatológicos en torno al concepto de justicia. La geografía condiciona la configuración de tres modelos políticos (atlante, ateniense, egipcio), de forma que su interacción plantea el problema de la relación con el medio: o no es más que una mimesis entre el actuar humano y el paisaje como su escenario, o bien una dialéctica entre el sujeto y la posibilidad de realización de su autenticidad.

Palabras clave: geografía imaginaria, mito escatológico, Timeo, Critias, Atlántida.

\begin{abstract}
The geography of the Timaeus-Critias is the final stage of a process through different eschatological myths around the concept of justice. The geography conditions the configuration of three political models (atlantean, athenian, egyptian); and their interplay raises the question of mimesis against dialectics. Any relation with the environment is one of two things: either a mimesis of human acts and the environment that serves as their stage; or a dialectics between the subject and the possibility of achievieng his o her authenticity
\end{abstract}

Keywords: imaginary geography, eschatological myth, Timaeus, Critias, Atlantis. 


\section{Objetivo}

No se trata de oponer una certeza menor a aquella ofrecida por el logos, sino de generar un relato que encaje lo probable con lo cierto, lo inmaterial con la fisicidad, y hacerlo mediante el artefacto persuasivo más eficaz. Dibujar geografías imaginarias en el discurso dialógico en el marco de un relato traído desde el mito constituye una parte demostrativa fundamental para la comprensión de la imbricación entre lo justo, lo político y lo anímico en Platón. Poco a poco la geografía evoluciona en sus diálogos para constituirse en un valor en sí misma que permita la contemplación directa de los modelos ontológicos y morales construidos a lo largo de su dialogar. Vinculada en un primer momento al mundo escatológico, deriva, mediante un proceso acumulativo de elementos formales e imaginativos, hacia la construcción de un escenario atemporal, pero en el que se fusionan discursos heterogéneos realizables en la historia y que miran al futuro político de la polis.

\section{El testimonio del Gorgias}

Su escenografía mitogeográfica más trabajada, más impresionante, es la dibujada en el Timeo-Critias. Pero el camino viene trazándose desde antes, en una sucesión de momentos que van desde la Justicia escatológica a la Justicia mitohistórica. La primera etapa es el Gorgias. La conversación entre Sócrates y Calicles deriva hacia la pregunta de qué sentido tiene participar en la vida pública: o buscar adular el deseo materialista de los ciudadanos o bien perseguir su virtud. Y luego se inicia un juego irónico, apuntando al juicio que Sócrates sufrió (521a). Él es un ejemplo vivo de las consecuencias de una práctica política que se concibe como el arte de satisfacer los deseos y placeres de los ciudadanos y no como el arte de realizar lo mejor para la ciudad. La política que seduce al cuerpo, que solamente busca dotarse de bienes aparenciales, mediante una dóxa aduladora, frente a la que llama a mejorar las propiedades del alma (521a). Sócrates se define como uno de los pocos atenienses que se dedica al verdadero arte de la política (521d). De aquellos que no buscan agradar a los demás construyéndoles un mundo urbano hinchado de bienes inmuebles, de rentas públicas, de grandes ejércitos, sino de justicia. Justifica así la lógica de su muerte: si no hay verdaderos ciudadanos no existen auténticos jueces. Ante un tribunal de ciudadanos moldeados desde la adulación, su condena sería segura. Sócrates buscaba procurarse su protección mediante el único medio de defensa que él consideraba válido: demostrar que su vida la había dedicado a no hacer nada injusto contra los dioses o los hombres, de modo que si existiera algún juez capaz de desmentirlo y condenarlo, le indignaría. Por el contrario, serenamente admitiría la muerte si su condena derivara de no poseer la retórica de la adulación 
(522d). La muerte mata al cuerpo, la injusticia destruye el alma, lo que le hace no temer a aquella y sí a esta (522e). Cerrado así el prólogo, el logos dialógico llama al mito (523a y ss.), que asoma para demostrar la posibilidad de un verdadero juicio, que necesita unas coordenadas extramundanas ${ }^{1}$. ¿Cómo es ese dónde? Lo primero es determinar bajo qué forma lo humano ocupará cada geografía. Separar el alma del cuerpo significa dejarla a solas, sin su envoltorio orgánico, sin sus vestiduras, sin las multiplicidades materialistas que han condicionado lo que se es, y en la mayoría de los casos se han constituido en su identidad. Gorgias dejará establecido para posteriores intentos que lo que se juzga es el alma, el juez no puede mirar al cuerpo para argumentar su decisión, sino a lo que verdaderamente se es. El cuerpo, y los parientes del muerto, sus aduladores, se quedan en la tierra (523e), en la geografia de la materialidad, donde se consume lo físico y su discurso falso. Minos, Radamantis y Éaco, llevarán a cabo su labor de enjuiciamiento del alma desnuda de los muertos, también como almas puras, «celebrarán los juicios en la pradera en la encrucijada de la que parten dos caminos que conducen el uno a las Islas de los Bienaventurados y el otro al Tártaro» (524a). El encuentro judicial es entre alma y alma, únicas entidades capaces de un logos dialógico puro. Por eso la geografía se realiza en un tridimensionalismo simple, categórico: Tierra, Islas y Tártaro. Es lo que la tradición decía, pero su significado ahora aparece desocultado. Platón despliega su ficción en base a una geografía homérica, rehecha de significados propios y órficos ${ }^{2}$. Topográficamente ofrece imágenes diferenciadas análogas a sus espacios morales: la superficie terrestre presenta una diversidad amplia, donde se dan todas las formas paisajísticas y climáticas tanto favorables como hostiles a la vida (es el marco de la libertad, de la mezcla de todos los modos de fisicidad y racionalidad). La pradera del más allá, es un lugar plano, equilibrado sobre una línea recta, sin adjetivación alguna, el lugar del juicio basado en la equidad: podrá ser arrojado a la profundidad tartárica, que evoca la oscuridad sin límites, la caverna, lo cerrado sobre sí mismo, lo no-geográfico; o bien, ser conducido a las Islas que presentan un cuadro paisajístico idealizado (prado de purpúreas rosas para Píndaro ${ }^{3}$ ), donde se da

\footnotetext{
${ }^{1}$ En este preámbulo al mito aparece también una característica de la geografía real urbana que da al lector una pista para poder entender el origen de la concepción paisajística de Platón. «Elogias a hombres que obsequiaron magníficamente a los atenienses con todo lo que éstos deseaban, y así dicen que aquellos hicieron grande a Atenas, pero no se dan cuenta de que, por su culpa, la ciudad está hinchada y emponzoñada. Pues, sin tener en cuenta la moderación y al justicia, la han colmado de puertas, arsenales, murallas, rentas de tributos y otras vaciedades de este tipo» (518e-519a). La adulación sofística genera un paisaje que coadyuva a la degeneración anímica, el discurso verdadero de los jueces ultramundanos la purifica en una geografía expiatoria. Este texto también es importante para entender la construcción urbano-cosmológica del Timeo-Critias. La geografía imaginaria surge también como antagonismo de la real.

2 Ver Casadesús (1997).

3 Trenos fr. 129.
} 
la abundancia de todo lo que únicamente puede hacer que la existencia sea un hecho paradisíaco. En el Gorgias se establece otra posición básica de la mitogeografía posterior, la Justicia se encarna a través de un vínculo con una realidad geomorfológica. Toda entidad (corporal o anímica) sucede necesariamente en una geografía que le ofrece las posibilidades de lo que se puede llegar a ser: post mortem, la inserción en una estabilidad determinada, bienaventurada o tartárica; ante mortem, la inclusión libre en un inestable orden geofísico terrestre. En el mito, geografía y sujeto se delinean de forma paralela para resolverse en un discurso persuasivo.

\section{El testimonio del Fedón}

Avancemos. Nos hallamos en una celda momentos antes de que Sócrates beba su cicuta. Ha sido sometido a la injusta justicia humana (a través de una legalidad cívica que no implica justicia) y ahora desea proclamar su esperanza, sobre la base de un logos mitificado, de que es posible la Justicia, eso sí, en un sujeto exclusivamente anímico (Fedón 63c). Conservando el camino fijado en el Gorgias, ahora diseñará una geografía que resuelva dónde ubicar esa alma inmortalmente entendida al modo platónico, lo que no aparecía en aquel, donde utilizaba la geografía tradicional del más allá sin más variación (los injustos van al Tártaro y los justos a la Isla de los Bienaventurados), en un diálogo más bien diseñado para superar una falsa justicia política y no para realizar una metafísica propia. En el momento previo al inicio del mito está demostrando que una entidad no admite a su contrario. Cuando la muerte toma el alma, esta no perece ni se transforma, sino que se ve obligada a escapar (oíchetai apión, se marcha lejos, 106e), pues su cualidad es la inmortalidad y la vida 4 . El alma vitaliza, diviniza algo, se da a algo que es su contrario, el cuerpo, lo que muere. Y ambas son realidades privativas. La perennidad del alma individual conlleva tener que prolongar su estado de individuación más allá del mundo terrestre, plantea tener que resolver de alguna manera el comportamiento diferenciado en ambos mundos, solucionar qué hacer con las adherencias humanas (al Hades va con su educación y su crianza terrestre, 107d) en relación con su sustancial divinidad, y además tener que crear diferentes espacios para visualizar discursivamente cada una de esas situaciones. Extinto el cuerpo, el alma, al no estar ya condicionada por su perspectiva sensible, es capaz de aceptar la Justicia, de autoregenerarse de acuerdo con las coordenadas de la verdad en sí. La pretensión del hombre debe ser segregar su voluntad de la de lo corporal, vivir como alma, pero en el aquí mundano donde la racionalidad debe alcanzar su maximidad. El dualismo pla-

\footnotetext{
4 «La divinidad, al menos, creo -dijo Sócrates-, y la idea misma de la vida y cualquier otro ser que sea inmortal, quedaría reconocido por todos que jamás perecerán» (106d).
} 
tónico no es un antagonismo irreconciliable sino un tránsito constantemente viajero entre dos geografías, dos formas anímicas que deben unificarse. Pero aquellas que ya hayan realizado ese trabajo por sí mismas en el mundo, que hayan sido capaces de sobrevivir a la justicia a favor de la Justicia, ¿cómo verán reconocido su esfuerzo? ¿Su premio requiere una nueva geografía de la vida? Aquí de lo que trato es de ver cómo en el Fedón es dónde se traducen las posibilidades de dar sentido al idealismo platónico.

El relato se fracciona en varias etapas. Un prólogo aclaratorio (107d-108c) para ese lector que espera oír un desarrollo tradicional avisa de qué modo quiere adentrarse en el inframundo. El camino no es sencillo y único como algún trágico simplifica. Es una vía compleja, laberíntica. Y además no se dirigen al Hades popularizado, sino a «muchas y maravillosas» regiones. Esto se soluciona no yendo el alma sola, sino con un guía personal, porque Caronte es un transportista colectivo de pago que solo cruza un río, mientras que si el objetivo es ser juzgado individualmente en un espacio intrincado (el ámbito de la Justicia con la mayúscula de las Formas), se necesita un daimōn, un tutor y conductor divino, un Caronte privado, exclusivo, que además de conocer a cada uno, no admita retribuciones ni discursos aduladores, pues ha de mirar directamente al alma, para asignarle su apropiado lugar escatológico. El análisis continúa (109b-110b) como si el observador viajara desde el espacio exterior y penetrara hasta la oscuridad más tenebrosa. Lo primero que contempla es la tierra en sentido propio, la situada en la superficie, mientras que después van apareciendo las cavidades y entre ellas, la nuestra, la heracleo-fásica («los que estamos entre las columnas de Heracles y el Fasis»). Esta es nuestra primera decepción, los humanos pensamos que vivimos en la superficie del planeta, cuando en realidad nuestro mundo se halla situado en el fondo de una de tantas oquedades que horadan su superficie esférica. Si pudiéramos llegar a «sacar la cabeza» fuera de la misma conoceríamos cual «es el cielo de verdad (alēthôs ouranòs) y la verdadera luz y la tierra en sentido propio (alēthôs gê), pues esta tierra, y las piedras, y todo el terreno de aquí, están corrompidos y corroídos, como las cosas del mar a causa de la salinidad» (109e-110a). Diferenciada la geografía auténtica de la copiada, prosigue situándonos (110b-111c) en la tierra propiamente dicha (gên autèn), donde todo es admirable y exuberante. Las piedras son puras, y sus colores son más brillantes y más numerosos que los que existen en las cavidades; los árboles y las plantas crecen proporcionalmente; poseen una gran abundancia de minerales, entre ellos el oro y la plata. Los hombres que residen allá arriba respiran éter, desconocen las enfermedades, viven más tiempo, aventajándonos en inteligencia y en todas las demás facultades. Poseen templos «en los que los dioses están de verdad, y tienen profecías, oráculos, apariciones de los dioses y tratos personales y recíprocos» (111c). El dios no aparece en una figuración ritual, o representado por una estatuaria, sino que es un otro para dialogar. 
El tercer escalón paisajístico recoge el mundo subterráneo que culmina en el Tártaro (expuesto en dos etapas: su descripción geográfica, 112e-113c; su valor expiatorio, 113d-114c). Multiplicidad de cavidades comunicadas entre sí por orificios más o menos estrechos por donde circula y fluye hacia el exterior, lava, fango $\mathrm{u}$ otros materiales y todo ello sometido a un movimiento a la vez circular y pendular. Frente al Hades estático ahora nos situamos en un espacio dinámico, cambiante tanto paisajística como anímicamente. Platón se sirve de la contraposición río/lago para hacer ver los diferentes momentos de mudanza de estado y de detención expiatoria. Tres espacios líquidos centran su estructura. La primera es una corriente, el Océano, el curso mayor y más extenso, que envuelve todas las demás; y las otras dos, son oquedades líquidas, el Tártaro y la laguna Aquerusíade, comunicadas entre sí. Aquellas almas que se estima que son irrecuperables a causa de la magnitud de sus crímenes permanecen en la primera indefinidamente. A la segunda, llegan las que después de vivir moderadamente necesitan expiar sus culpas, conducidos por la corriente de Aqueronte. Igualmente recibe a los criminales por la corriente del Cocito, y a los que maltrataron al padre o a la madre por la del Piriflegetonte. Han pasado una temporada en el Tártaro, de modo que para completar su purificación esperan ser perdonados por sus víctimas en la laguna. El Tártaro es una cavidad situada en la extremidad abismal donde abocan todas las corrientes de la tierra, es la maximidad de la mezcla, frente a la maximidad de la pureza material que se encuentra en la superficie. Las corrientes llevan a su laguna, la estanqueidad, el lugar donde el alma puede elegir, rectificar, autoanalizarse (como en la cavidad heracleo-fásica cuyo punto focal es la «laguna mediterránea» a la que abocan todos los ríos, desde el mundo bárbaro al mundo civilizador $)^{5}$.

Las tres corrientes hídricas en su discurrir adoptan las características de los medios que atraviesan, en un proceso que recuerda al alma, que nace pura, pero cuya vida la puede contaminar. El Aqueronte discurre por desiertos, el Piriflegetonte, «desemboca en un terreno amplio que está ardiendo con fuego abun-

\footnotetext{
5 Esta contraposición río-lago tiene su precedente en la oposición órfica de fuente-lago, que aparece en las laminillas de oro encontradas en enterramientos, y donde se describe el camino del iniciado al más allá (ver su edición y comentario en Bernabé y Jiménez San Cristóbal, 2001, y para este tema, el cap. I). El muerto encontraba en su viaje al Hades un ciprés blanco a cuyo pie manaba una fuente, innominada en las laminillas, pero identificada como la del Olvido, de la que debía apartarse, pues de beber en ella perdería su memoria, el recuerdo de su iniciación y del mundo, por lo que debería volver a él, reencarnándose, e iniciando un nuevo ciclo de vida temporal, que supone ignorancia e infelicidad. Tras la fuente prohibida, se hallaba la laguna de Mnemósine custodiada por guardianes sobrenaturales, que pedían al iniciado una contraseña para poder beber en ella. Es agua de salvación, ya que otorgaba la inmortalidad, la liberación del ciclo de reencarnaciones. Tal y como señalan los autores citados, «la verdad implica una memoria total que excluye del alma el olvido, léthèe, igual que en la geografía escatológica el agua de la Memoria excluye el agua del Olvido» (op. cit., p. 62). Una imagen que volveremos a encontrar en el relato del Timeo-Critias donde el olvido del pasado mítico supone la imposibilidad de contemplar al alma en su excelencia.
} 
dante, y forma una laguna mayor que nuestro mar, hirviente de agua y barro. Desde allí avanza turbulento y cenagoso» (113a), y acaba aflorando como lava en la tierra habitada (ecuméne). El Cocito desemboca en la laguna Estigia, lugar terrible y salvaje, y después de salir de ella, contagiado de su energía (dynámeis), avanza en sentido opuesto al Piriflegetonte. Desolación desértica, turbulencia hirviente, salvajismo, analogías de desarmonía, incivilización, desorden, contrariedad de lo cósmico y su armonía lucífera.

Los que han llevado una vida piadosa (hosíōs biōnai), «liberándose de esas regiones del interior de la tierra y apartándose de ellas como de cárceles, ascienden a la superficie para llegar a la morada pura (katharàn oíkēsin) y establecerse sobre la tierra» (114c). A partir de aquí también el dualismo se rompe, desde la tierra auténtica y la tierra subterránea hacia la sin-tierra6. La maximidad humana, los filósofos, viven sin cuerpo «y van a parar a moradas (oikēseis) aún más bellas que ésas, que no es fácil describirlas (dēlôsai, hacer visible) ni tampoco tenemos tiempo suficiente para ello en este momento». Indudablemente se trata de una región terrestre?, pues el propósito es objetivar la existencia de Justicia en el mundo de la vida. El hecho de que vivan sin cuerpo no es más que una simbolización de la realidad que habían vivido cuando lo tenían. La filosofía los libera y purifica, de modo que al llegar al Hades buscan lo semejante 8 , por lo que necesitan un lugar de convivencia directa con los dioses, que Platón no describe. Pero precisa su presencia, que sea visto de alguna forma. No es el mundo de la apariencia ni el ideal, sino un mundo anímico donde acontece la vida como individuación pura. Renuncia al logos de ese lugar y lo prefiere desubicado, no descrito, no geográfico, pero mantiene su credibilidad por el hecho mismo de su necesidad para poder «hacer ver» que hay Justicia.

¿Sin una geografía asociada, tiene sentido el idealismo platónico en esta composición discursiva de espera consoladora? ¿Para qué intentar una vida justa? ¿Para qué la vida del sabio socrático? La desesperanza platónica nos dice que realizar la Justicia en el mundo solo es posible individualmente y sin más recompensa que la propia satisfacción, pero en la mitogeografía es posible un lugar colectivo, una polis de almas. Aquella alma recuperable porque en su vida terrestre no ha renunciado totalmente a su esencia divina, sufre el castigo como si se tratara de un cuerpo sentiente en un paisaje donde tienen lugar las mezclas purificadoras: fuego, agua, tie-

\footnotetext{
${ }^{6}$ Friedländer (1989, p. 250), señala que «la oposición metafísica entre mundo de las ideas y mundo de la apariencia está aquí bajada a la Tierra y se desarrolla en el contraste de valor de la 'verdadera Tierra' y nuestro 'ecuméne' en el suelo de la oquedad».

7 Por el contrario, Robin (1965, p. 97), n. 1, propone los astros.

8 «Pues a partir del opinar en común con el cuerpo y alegrarse con sus mismas cosas, se ve obligada, pienso, a hacerse semejante en carácter e inclinaciones a él, y tal como para no llegar jamás de manera pura al Hades, sino como para partirse siempre contaminada del cuerpo, de forma que pronto recaiga en otro cuerpo y rebrote en él como si la sembraran, y con eso no va a participar de la comunión con lo divino, puro y uniforme.» (Fedón 83d-e).
} 
rra, aire, combinados, se transforman en lodo, lava, vapor, llama. Por el contrario, el alma corporeizada es sometida a un proceso de depuración sensible para que su voluntad se interiorice, para que limpiándola de toda materialidad, sea ella en su mismidad. El objetivo es liberarse de esas regiones-cárceles (114b), que maximizan lo mundano, para que sometidos a esa inmersión extrema, ambicionen otra geografía donde habitar excarcelado. La ética individualista heredada de Sócrates (aquella que busca indirectamente el interés colectivo a través del cuidado de los ciudadanos individuales, Apología 23b), obliga a la rotura de la neutralidad geofísica del Hades tradicional. El sujeto mantiene su individualidad en un más allá de su morfología específica corporal que sucede en su historia terrena. Dotar a cada alma de una historia particular requiere contextualizarla escatológicamente con elementos reconocibles por los lectores y capaces de transmitir y condicionar sus decisiones éticopolíticas futuras.

\section{El testimonio de la República}

La República apuntará las nuevas necesidades geográficas de su teoría filosófi$\mathrm{ca}^{9}$. Ahora ya dispondrá de unos personajes concretos a los que tiene que emplazar inmortalmente, los guardianes filósofos. Pero no lo hará en este diálogo. La geografía mítica que nos ofrece en él, a través de la fábula de Er (614b y ss.), es de una gran simplicidad ${ }^{10}$. Un prado de acogida de las almas de los muertos en el que hay dos pares de agujeros, unos arriba, por dónde entrarán y saldrán los que vayan al cielo a ser recompensados, y abajo, los que entrarán y saldrán de ser castigados. No importa saber qué hay tras ellos. El estadio siguiente es dirigirse al huso de la necesidad, donde las esferas cósmicas unidas por la pura luz son movidas por tres Parcas armonizadoras de la música celestial. Láquesis, la que canta el pasado, les ofrece modelos de vida de entre los que escogerán aquel que esté más de acuerdo con sus aprendizajes humanos, «éste es el comienzo, para vuestro género mortal, de otro ciclo, anudado a la muerte». Los bajados del cielo y los subidos de lo subterráneo se equivocan al elegir porque ambos no han ejercido la filosofía, además de que se

\footnotetext{
9 Es imposible tratar en este artículo todas las geografías platónicas. Citaré que en el Politico Platón se limita a una geografía tópica de la edad de oro en el marco de un mito que mira al cosmos y no a la tierra. En el Fedro (249a-b) utiliza puntualmente una contraposición celeste-subterráneo. El papel de la caverna en la República retoma los simbolismos tartáricos fedonianos. Las Leyes es muy dependiente de los postulados del Timeo-Critias.

10 En el mito Platón sigue los mismos presupuestos que los diálogos anteriores sobre la necesidad de crear un espacio para la Justicia, tal como afirma Salvador Mas (2009, pp. 154-155), el sentido del viaje de Er se puede resumir en que «el alma debe ser inmortal para que el justo obtenga su recompensa y el injusto su castigo, tiene que haber algún lugar donde se cumplan estos premios y castigos, la pena para la máxima maldad e impiedad debe ser proporcional al delito, esto es, máxima, o sea, eterna».
} 
encuentran bajo el efecto de su estado post-expiación, los unos, por no sentir el sufrimiento, mientras que los segundos por haberlo sufrido en exceso (619c-d). Únicamente los convertidos a la filosofía en la tierra no se ven afectados por los estados expiatorios post mortem. Aquellos, incluso allí, se acogen a su corporalidad, estos, la han superado. La geografía mundana, inframundana o supramundana, no influye en los filósofos, pero sigue constituyendo el eje sobre el que se dota de sentido la realización de la Justicia. A renglón seguido en el desierto del Olvido, «a través de un calor terrible y sofocante» borrarán de la memoria todo. Nos quedan para el siguiente mito dos elementos nuevos: el ciclo y la elección, que modificarán el objetivo de la mítica geográfica.

\section{El testimonio del Timeo y del Critias}

Al guardián filósofo le aguarda una geografía tangible. La trilogía TimeoCritias-Hermócrates irrumpe como una reescritura del mito geográfico del Fedón y del mito cósmico de la República11. Sócrates pide ver a los guardianes filósofos en acción épica (Timeo 19b), para lo que necesita un nuevo mundo vinculado al de su contemporaneidad. Tomando como núcleo la Atlántida, Atenas y Egipto, Platón nos traslada a un mundo originario a partir de una redefinición de la geo-escatología predecesora. Continúa en su insistente idea de traer a nuestra alma la posibilidad de la Justicia, pero ahora a partir de trasladarnos, no al mundo ultramundano, sino a un tiempo histórico originario, para hacernos ver que lo que creemos muerto en nuestra alma, la idealidad, puede ser revivificado. La verdadera expiación es una anámnēsis desde el aquí.

Recorriendo la geografía terrestre timeocritiana desde su perímetro circular, aparece, en primer lugar, un continente circunterrestre, a continuación, el Océano, donde se alza la Atlántida, y en su centro, nuestro hábitat continental. Platón tiende un puente literario para que el lector lo cruce, creando un sistema de relaciones entre estas ecuménai: «...vuestra ciudad detuvo en una ocasión la marcha insolente de un gran imperio, que avanzaba del exterior, desde el océano Atlántico, sobre toda Europa y Asia. En aquella época, se podía atravesar aquel océano dado que había una isla delante de la desembocadura que vosotros, así decís, llamáis columnas de Hércules. Esta isla era mayor que Libia y Asia juntas y de ella los de entonces podían pasar a las otras islas y de las islas a toda la tierra firme (épeiron, conti-

11 Pradeau (1997, pp. 259-263), si bien establece que el estudio del mito del Fedón es indispensable para la comprensión del Critias, no hace una interpretación simbólico de la geografía fedoniana en relación con la timeocritiana, y concluye que la geografía regional determinará la constitución política de las dos ciudades, llegando a afirmar que el objeto del Critias no es el conocimiento del hombre sino esa relación determinativa entre la ciudad como totalidad y el territorio. 
nente) que se encontraba frente a ellas y rodeaba el océano auténtico (alēthinón pónton), puesto que lo que quedaba dentro de la desembocadura que mencionamos parecía una bahía con un ingreso estrecho. En realidad era mar y la región que lo rodeaba totalmente podría ser llamada con absoluta corrección tierra firme (épeiros). En dicha isla, Atlántida, había surgido una confederación de reyes grande y maravillosa que gobernaba sobre ella y muchas otras islas, así como partes de la tierra firme» (Timeo 24e -25a). El escenario se configura a partir de la dialéctica interior-exterior, Mediterráneo-Atlántico, con el punto intermedio de las Columnas de Hércules (por el contrario, en el Fedón lo hercúleo-fásico contenía todo lo humano). De más allá del estrecho viene lo nuevo (Timeo 25c, Critias 114c, 108e). Lo atlante es lo exterior y lo ateniense-egipcio lo interior, la ecuméne mítica frente a la real. Las C. de Hércules en el mundo originario se convierten en una estación más hacia lo conocido. Pierden su tradicional relevancia iniciática hacia lo extra-ordinario. En el Timeo-Critias el océano no está poblado por islas fabulosas donde habitan personajes mitológicos, sino por los atlantes y otros pueblos isleños, conocidos por los habitantes de Gadiros y, por tanto, reconocibles y nada misteriosos ${ }^{12}$. Era un espacio capaz de ser surcado con los medios de navegación de la época, permitiendo su colonización, su asimilación. El mundo dibujado por Platón incitaba a la exploración y al conocimiento, tal y como el Egeo servía de puente entre Grecia y Oriente. El océano pasa a ser un espacio abierto al hombre, el escenario donde se mueven los atlantes y el resto de pueblos con los que tienen intensos contactos comerciales.

La dinámica física impone su propia necesidad y acaba con todo en un solo día, un diluvio y un terremoto provocan el hundimiento de la Atlántida (se supone que la isla-continente arrastraría consigo al resto de las islas del océano, dejando a salvo el continente cincunterrestre) y la destrucción de Atenas, de modo que todo se perdió para la memoria y sobrevino la geografía positiva, el ciclo de la actualidad13. El océano se convierte así en un lecho tartárico, fangoso, infranqueable. En la geografía exploradora y comercial griega el fango expresaba la necesidad de cerrar la ecu-

\footnotetext{
12 «Al hermano gemelo, nacido después de él, a quien tocó en suerte la parte extrema de la isla, frente a las Columnas de Hércules, hasta la región llamada hoy día en ese lugar Gadirica, le dio en griego el nombre de Eumelos, y en la lengua del país, Gadiros» (Critias, 114b). Para los griegos Gadirica (de la Gades fenicia) era el último punto de referencia conocido antes de internarse, o bien en el inexplorado océano, o bien en las tierras del norte y sur, igualmente desconocidas (Millán León, 1998, p. 136.). Se convierte en un recurso «estético-literario para delimitar el alcance de la ambición humana pero no como un real límite físico a las posibilidades de navegación» (Ibidem, p. 93).

13 En el Timeo-Critias Platón desarrolla una clasificación de las catástrofes que renuevan periódicamente la Tierra. Suceden inevitablemente sin que los dioses intervengan en su causalidad. Existen catástrofes mayores y menores, por fuego, agua o debidas a terremotos (Timeo 22c-e, 25d). En ninguno de estos casos Egipto se ve afectado. Por otro lado, el fango oceánico que convertía al Atlántico en infranqueable era una creencia muy extendida: Aristóteles, Meteorológicas 354a10-20; Pseudo Escílax, Periplo I 112; Píndaro, Olímpicas III 41-45.
} 
méne sobre sí misma, de crear una barrera conceptual que diera sentido a la incapacidad técnica de resolver la navegación oceánica. En Grecia la simbolización mítica del fango penetra por la vía del orfismo. Los no iniciados en sus misterios o los que no habían cumplido debidamente con sus ritos, una vez muertos, sufrían tres formas de castigo: la permanencia en un lugar oscuro y fangoso (inmovilidad, suciedad, indefinición); el llevar agua en un cedazo a una tinaja agujereada (el esfuerzo inútil, la repetición constante de lo mismo sin sentido); el ataque de monstruos, fieras, serpientes, Furias, Harpías, que no provocaban la muerte (dolor permanente, destrucción del cuerpo) ${ }^{14}$, mientras que los iniciados disfrutarían de la luz y la felicidad en la pradera de los bienaventurados. El fango-castigo fedoniano aparece como fango-barrera.

El argumento de reversión (el hoy, desgastado por el tiempo, nos remite a un mundo primordial puro) funciona aquí también: el fango actual, compuesto de agua/tierra, retorna en el mundo originario a su estado básico, disociándose en dos de los elementos compositivos de toda materia. Una prueba fáctica de la verdad del ayer. Pero las consecuencias van más allá. En el antes originario el Atlántico era como un mar Egeo inmenso. Ahora la tierra verdadera es inaccesible. Sin embargo, esa imposibilidad puede ser superada. Platón lanza implícitamente el mensaje de que podemos recuperar las tierras habitadas paradigmáticas, Atlántida/Atenas y la tierra verdadera. Todas ellas están al alcance de una construcción discursiva, racional, anamnésica. Nos viene a decir que el mundo físico sufre modificaciones con el paso de los ciclos naturales, cambios que son inexorables, pero que no ocurre lo mismo con la psique humana que sí puede ser renovada por la acción de la educación y la política.

A lo que asistimos en el Timeo-Critias es al ascenso de la cavidad heracleo-fásica fedoniana hasta situarse en un mismo plano con la superficie, generando una tierra uniforme15. Platón hace aflorar la corriente oceánica, y la rodea de una franja terrestre que es fácilmente accesible, colonizable desde el Atlántico, el océano auténtico (Timeo 24e). Aquí se encuentran los dos mundos antes incomunicados. Interpretando la función simbólica de esa igualación, vemos que el mundo de la apariencia se presenta sobre el mismo plano que el mundo ideal. Parece como si Platón, una vez nivelados esos dos espacios, hubiera hecho que los hombres auténticos del Fedón adoptaran la forma de atlantes y atenienses ideales, en una emigra-

\footnotetext{
${ }^{14}$ La información sobre el castigo fangoso proviene del mismo Platón. En el Fedón (69c) al hablar de los cultos mistéricos afirma que quien llega impuro y no iniciado al Hades yacerá en el fango. En la República (363d) informa que a los sacrílegos e injustos, los sumergen en el fango en el Hades y los obligan a llevar agua en una criba. El fango es metafóricamente utilizado para expresar la detención, la ceguera racional: sólo el método dialéctico puede hacer ver a un alma sumergida en el fango ignorante, bárbaro (borborōi barbarikôi), cual es el camino hacia la verdad (Rep. 533d).

15 Brisson (1992, p. 227, n. 80) anota que uno podría estar aquí tentado de considerar la tierra verdadera timeocritiana como una glosa de la fedoniana.
} 
ción simbólica cargada de contenido moral y paradigmático desde la tierra verdadera hacia el resto del mundo. En ese mundo de la apariencia sitúa dos culturas de hombres auténticos que ejercen la supremacía sobre las restantes: una, degenerará y acabará derrotada militarmente, como el instrumento necesario para alcanzar su regeneración, mientras que la otra, la vencedora, era la que había sabido permanecer estable en su excelencia. Si en el Fedón solo los hombres «auténticos» convivían con los dioses, ahora todos los hombres conviven entre sí, en un juego de culturas en el que unas consiguen, y otras simplemente intentan, alcanzar la Justicia.

En este mundo diseñado por Platón se entremezclan diferentes planos conceptuales y geofísicos, formando el medio apropiado para ubicar su historia ejemplar. Es un marco en el que las acciones humanas actúan construyendo su propio destino, situándose ante la posibilidad de alcanzar su excelencia o su degeneración. Aquí la mitogeografía ya no sirve únicamente a la escatología, sino que posee dos momentos, uno suprahistórico con su geografía originaria, y otro actual con su geografía fruto de la erosión mundana. Una, ha muerto para la memoria, pero la otra, la evoca. Una es un modelo para la expiación de la otra. Esta traslación de modelos geográficos desde la escatología a la mito-historia, le permite también a Platón releer su «verdadero juicio» a las almas como un «juicio histórico» a los pueblos (Atenas ideal actuará como paradigma de lo justo y como juez que restaura el equilibrio del mundo originario mediante el castigo, la derrota militar de los atlantes). La geografía del Timeo-Critias compone un espacio para la convivencia entre el hombre real y el ideal, pero en un tiempo mítico, equivalente al tiempo post mortem, pero en uno ficticio ante mortem. Por ello está hecha de una mezcla de componentes geoescatológicos y geofísicos, porque el hombre ahora tiene que limpiar su alma como fruto de un proceso anamnésico realizado desde su presente. En el mito escatológico el alma olvidaba su paso por la geografía expiatoria, aquí, en cambio, se hace necesario que la geografía del presente sea entendida como un dato para ser revertido hasta su origen. Ese hallazgo no solo es verificado en un marco dialógico sino físico. La geoescatología no permitía esta aventura racional, pues situaba al hombre en un espacio no recuperable, creíble únicamente a través de un ejercicio compositivo literario.

Este mecanismo funciona también en otro sentido. Ahora, al igualar los dos niveles humanos fedonianos, se facilita el encuentro de todos los hombres en la idealidad. Al situarla en la historia mítica ya no se halla en el mundo de las Ideas sino en la memoria de los atenienses y en la memoria escrita de los egipcios ${ }^{16}$, pues ambos la conocieron cara a cara. En la trilogía se trata en este último caso de constituir una memoria mítico-histórica que se halla más cercana que la memoria divi-

\footnotetext{
16 En el Timeo Platón escribe que los egipcios recogieron por escrito los hechos ocurridos en ese tiempo mítico. Un sacerdote del templo de Sais se lo transmitirá a Solón, que lo contará en su círculo familiar. No llegará a acabar su proyecto de escribir un poema sobre el tema.
} 
na del alma traída desde un supramundo al que retornará después de la muerte del cuerpo y que ha sido definitivamente olvidado (como sucede en los mitos de los diálogos precedentes). Lo que nos dice ahora Platón es que en un tiempo mítico el alma conoció lo divino como una alteridad humana de convivencias (atlante-atenienseegipcia) que pueden ser restituidas mediante su reversión. Es un logos épico, fácilmente comprensible, verosímil, que nos da la mano desde elementos creíbles y nos propone una nueva identidad recuperada de la memoria histórico-mítica. Los atenienses ideales poseen las características de los habitantes del verdadero continente del Fedón, pero han sabido constituirse en paradigma para todos los hombres, apartados de los demás, en la acrópolis, como en su propia «oquedad». Por el contrario, la isla continente es un espacio abierto, y por ello ese carácter intermedio, mestizo, que define la naturaleza atlante, está perfectamente simbolizado en su ubicación. Ese mundo no existía, pertenecía a un pasado que únicamente podía ser revivido en la memoria conceptual, discursiva. Quería provocar un hallazgo desde el logos dialógico, como estímulo para la mejora moral y política del alma individual, para lo que era necesario establecer una geografía de los Estados épicos delimitada analógicamente en relación con su hacer político.

Una vez desplazada la cavidad heracleo-fásica hacia la autenticidad, el siguiente paso es la descripción de las tres territorialidades que ahora definen este nuevo mundo, que a su vez, son ordenadas de acuerdo con los objetivos de la trilogía17. Atlántida es mayor que Libia y Asia juntas (Timeo 24e; Critias 108e) ${ }^{18}$, y su medio ambiente es explicado a partir de la grandiosidad (Critias 114d-115c). Su pintura tiene los trazos de una oposición decidida por su finalismo moral: a la autosuficiencia exuberante de su naturaleza («estaban provistos de todo de lo que era necesario proveerse en la ciudad y en el resto del país») se le opone la acción del hombre, el comercio («aunque importaban mucho del exterior a causa de su imperio, la mayoría de las cosas necesarias para vivir las proporcionaba la isla»). En un mundo autárquico que les permitiría vivir aislados, su degeneración les lleva a utilizar su potencial natural, mercantilizándolo, vehiculizándolo como instrumento de conquista. Su geografía les dota del poder necesario, tanto para purificar su alma como para lo inverso.

Fuera de las extremidades de oriente u occidente, del norte y el sur, Platón nos recuerda que Atenas es el modelo del justo medio geográfico, lo que viene a deter-

17 Pradeau (1997, pp. 62-63), ha señalado cómo la descripción de Atenas sigue un patrón textual enumerativo, mientras que la de la Atlántida es narrativizado. En el primer caso, derivado de su estabilidad, de la intervención mínima que los atenienses realizan en el territorio; mientras que en el segundo caso, derivado de su sometimiento al orden diacrónico de las modificaciones que van introduciendo en la ciudad las sucesivas generaciones de atlantes. Pero lo enumerativo también puede ser acumulativo, lo que sería más típicamente atlante.

18 Heródoto describe un mundo formado por Europa, Asia y Libia, de modo que la extensión de la primera es igual a la suma de las otras dos (II 5ss; 158, 4 y IV 36 ss). 
minar el carácter armonioso de sus habitantes ${ }^{19}$. Señala que sus fronteras «se extendían hasta el Istmo, y en el resto de la tierra firme hasta las cimas del Citerón y el Parnes y que el límite bajaba con la Oropía a la derecha y a la izquierda bordeando el Asopo desde el mar» (Critias 110d-e). Para delimitar el límite oeste Platón se inspira en la tradición, cuando la Megaride pertenecía a los atenienses ${ }^{20}$. En cuanto a la frontera norte, Platón señala, en primer lugar, una serie de sistemas montañosos, y el Asopo, el único río perenne del sur de Beocia, que atraviesa de este a oeste el Helicón. La mención de esta doble frontera, aparte de por evidentes razones geográficas, está fundada en motivos de tipo histórico, ya que separa el Ática de otra de las polis que entrará en pugna con Atenas durante el s. IV, Tebas (la ciudad de Oropo constituía una antigua reivindicación tebana ${ }^{21}$ ). Las fronteras del Ática originaria rompen barreras políticas y temporales. Platón establece los límites en función de los dos enemigos fundamentales de Atenas, Esparta y Beocia, que le disputaban la hegemonía sobre Grecia desde la Guerra del Peloponeso. Traslada al mundo mítico los anhelos colectivos de la contemporaneidad política ${ }^{22}$. De nuevo el argumento de reversión: la «pequeñez» de la Atenas de hoy es un síntoma de su grandeza pasa$\mathrm{da}^{23}$. La geografía del hoy puede ser leída racional e idealmente, porque como en todo organismo su desarrollo y evolución es un proceso de distanciamiento con respecto al paradigma.

19 Heródoto I 142,1; Aristóteles, Política 1327b; Timeo 24c-d. Todos ellos siguen a Hipócrates, Sobre los aires, aguas y lugares 23 y ss., donde desarrolla la medicina meteorológica.

20 Pausanias, I 39, 4; III 15, 5. Todo ello en concordancia con la datación mítica expuesta en el Critias (110b), pues la guerra entre Atenas y Atlántida se dio en tiempos de Cécrope, Erecteo, Erictonio, Ericsiton y los restantes reyes anteriores a Teseo.

21 Durante la guerra del Peloponeso los beocios se apoderan de Oropo (412 a.C.) con la colaboración de ciudadanos de Eretria (en Eubea) que tramaban la salida de la isla de la confederación ática. Tomar Oropo constituía una etapa para apoderarse de la isla, punto vital para los suministros de grano a Atenas a través de Decelia (Tucídides VII 28), además, dominándola, se podía atacar el Ática desde zonas muy diversas. Eubea daba a los atenienses más ingresos que toda el Ática. Así la pérdida de la isla supuso uno de los momentos más duros de la guerra, pues ni siquiera la derrota en Sicilia les había atemorizado antes tanto (Tucídides VIII 96; Aristóteles, Const. de Atenas XXXIII, 1). Posteriormente, pasará a estar bajo la influencia de Atenas (Isócrates XIV 20). Después de Leuctra (371), comienzo de la hegemonía tebana, la isla de Eubea abandona la Segunda Liga Marítima Ateniense. En el 366, Temison, tirano de Eretria, se apodera de Oropo y se la entregan a los tebanos. Por su parte, intentando recuperarla, los atenienses solicitaron la ayuda sin éxito de sus aliados peloponesios. La política exterior ateniense antitebana sufre un duro golpe, por lo que se opta por otra táctica: realizar concesiones a Tebas, aceptando la posesión de Oropo y su posición hegemónica en Beocia, a cambio del derecho de Atenas sobre el Queroneso.

22 Brisson (1992, p. 383, n. 60 y 64).

23 «En comparación con lo que había entonces, lo de ahora ha quedado... semejante a los huesos de un cuerpo enfermo, ya que se ha erosionado la parte gorda y débil de la tierra y ha quedado sólo el cuerpo pelado de la región. Entonces, cuando aún no se había desgastado, tenía montañas coronadas de tierra y las llanuras que ahora se dicen de suelo rocoso estaban cubiertas de tierra fértil. En sus montañas había grandes bosques de los que persisten signos visibles, pues en las montañas que ahora sólo 
Platón acude a la geografía positiva y relee a Heródoto para transformar su relato viajero en mito. ¿El Egipto timeocritiano es una creación literaria creada ex profeso y de forma análoga a los otros escenarios? Heródoto discute el concepto de los jonios sobre Egipto24. Según estos, Egipto es solo el Delta y además es el Nilo el que delimita la separación entre Asia y Libia. Ambas afirmaciones son para Heródoto contradictorias y erróneas. El historiador concluye que Egipto es todo el territorio habitado por los egipcios, es decir, el Delta y las tierras a un lado y otro del Nilo. Para aclarar su posición pasa a describirlo, configurado por las cinco bocas del río 25 . Hasta la ciudad de Cercasoro (próxima a El Cairo) discurre en un solo cauce y a partir de ella se divide en tres bocas naturales: Pelusia, Canobica y Sebenítica, de las que se han formado otras dos artificiales, Bolbitina y Bucólica. Además, en cuanto a su organización administrativa, menciona que se encontraba dividido en seis nomoi (divisiones territoriales): «Busirita, Saíta, Quemita, Papremita, la isla que se llama Prosopítide y la mitad de Nato» 26 . La traducción de la frase con la que comienza Critias su descripción de Egipto (Timeo 21e) ha sido controvertida 27 . Platón da a entender que el cauce del Nilo se bifurca en dos cursos que delimitan las fronteras de una región que constituye el Saítico, sin mencionar todo el conjunto de bocas y de nomoí que conforma el Delta en su conjunto. Sabemos que Platón tenía conocimientos suficientes para poder situarlo en su ubicación real, pero, como señala Reynard28, lo emplaza mucho más al sur, en la Prosopítide, en el lugar donde se bifurca el Nilo entre los brazos Canópico y Pelusio ${ }^{29}$. Platón deforma conscientemente la situación del nomós, componiendo un área geográfica mucho más amplia de la que en realidad ocupaba.

También reinterpeta su fuente herodótea en otro punto. Los sacerdotes le cuentan al historiador que novecientos años atrás en la zona de Menfis era necesario que

tienen alimento para las abejas se talaban árboles no hace mucho tiempo para techar las construcciones más importantes cuyos techos todavía se conservan... Además, gozaba anualmente del agua de Zeus, sin perderla, como sucede en el presente que fluye del suelo desnudo al mar; sino que, al tener mucha tierra y albergar el agua en ella, almacenándola en diversos lugares con la tierra arcillosa que servía de retén y enviando el agua absorbida de las alturas a las cavidades, proporcionaba abundantes fuentes de manantiales y ríos, de las que los lugares sagrados que perduran hoy en las fuentes de antaño son signos de que nuestras afirmaciones actuales son verdaderas (Critias 111b-e).

24 II 15 y ss.

25 II 17, 3-6.

26 II $165,1$.

27 Ver Reynard (2000).

28 Op. cit. p. 142.

29 Precisamente en esta zona se encontraba la isla Posopítide entre las bocas Canóbica y Sebenítica y un canal que las unía. En este nomo tuvo lugar la derrota de los atenienses en Egipto citada por Tucídides y Heródoto, entre otros, es citado por Platón en Menexeno (241e). Los hechos tuvieron lugar en el marco del apoyo que los atenienses llevaron a cabo a la sublevación egipcia contra el dominio persa, de modo que fueron sitiados en la isla citada durante año y medio, en el 458/7 a.C. En este área también sabemos que Platón conocía la ciudad de Naucratis, cercana a Sais (Fedro 274c). 
el río en su crecida alcanzara un mínimo de ocho codos para que pudiera inundar las tierras circundantes y que en la actualidad necesitaba subir quince o dieciséis. «Si esa región sigue ganando altura en semejante progresión y continúa creciendo del mismo modo, esos egipcios, a mi juicio, al no inundarla ya el Nilo, sufrirán, en todo el tiempo venidero, lo que, en cierta ocasión, ellos dijeron que sufrirían los griegos. Resulta que, al saber que todo el territorio griego se riega con agua de lluvia y no con ríos como el suyo, afirmaron que los griegos, frustrados un día en su [gran] esperanza, padecerían un hambre terrible. Esta afirmación quiere decir que, si la divinidad no quisiera enviarles lluvia, sino mantener la sequía, los griegos serían presa del hambre, ya que, efectivamente, no tienen ningún otro medio de conseguir agua como no sea por la gracia de Zeus; solo así» 30 . En el Timeo (22e) el sacerdote egipcio se expresa en términos muy parecidos: «En esta región, ni entonces ni nunca fluye el agua de arriba sobre los campos, sino que, por el contrario, es natural que suba, en su totalidad, desde el interior (kátōthen, de abajo) de la tierra. Por ello se dice que lo que aquí se conserva es lo más antiguo». Es la estabilidad de las crecidas mantenidas durante más de nueve mil años (el período de tiempo transcurrido desde la época mítica hasta Platón) lo que proporciona a Egipto esa capacidad de conservación de la memoria, pues no le afectan las aguas de Zeus, mucho más inestables, irregulares y a veces violentas, que provocan la pérdida del suelo fértil, como ha sucedido en Grecia desde la época mítica (Critias 111d). Platón obvia la reflexión herodótea sobre la situación irremediablemente degenerante de las crecidas del Nilo ${ }^{31}$. La supuesta estabilidad ambiental que alega para basar la conservación de lo antiguo que llevaban a cabo los egipcios, no sería sino una creación ad hoc, para cimentar la oposición arriba/abajo, lluvia/crecida, que define la geografías griega y egipcia.

El sacerdote también alude a las causas de las crecidas del Nilo ${ }^{32}$. A pesar de conocer las teorías existentes, Platón parece aceptar una diferente al señalar la procedencia natural de las aguas desde «abajo», no alegando como causa, fenómeno climático alguno (habría que volver al Fedón para encontrar su sentido en el movi-

\footnotetext{
30 II $13,2-3$.

$31 \mathrm{Si}$ en novecientos años el nivel del río ya necesitaba subir ocho codos más, en nueve mil serían ochenta. En realidad, el lecho asciende en la misma progresión que las orillas.

32 Heródoto expone varias teorías de origen griego, pues reconoce que no pudo obtener explicación alguna de los mismos egipcios (II 19-27). Comenta las siguientes: los vientos etesios impiden que el agua del río fluya al mar provocando su subida (Diodoro I 38,2, atribuye esta teoría a Tales de Mileto); al encontrarse el origen del río en el Océano, el flujo y reflujo de este influiría en aquel; y por último, la fusión de la nieve en Libia. Heródoto desecha todas ellas y propone que el sol en la época invernal se desvía de su trayectoria habitual y se dirige hacia el sur, a Libia, donde absorbe (evapora) el agua del río. Por el contrario, en el verano el sol vuelve a su posición natural y absorbe el agua de todos los ríos. De esta forma, en invierno el Nilo sufre una disminución de su caudal, mientras que en verano, posee, a pesar de la evaporación de la estación, su caudal natural (que es el del momento de la crecida). Según Anaxágoras la causa era la nieve derretida en Etiopía a quien sigue Eurípides en su tra-
} 
miento tartárico de columpio que contagia a todas las corrientes subterráneas). La estabilidad de este proceso, frente a la irregularidad del agua de «arriba», sometida a la voluntad cambiante y arbitraria de Zeus, ¿se corresponde con la realidad del comportamiento del Nilo? Gran parte de las hambrunas que se sufrían en Egipto eran causadas por una insuficiente o excesiva crecida del río, lo que a su vez provocaba fuertes tensiones sociales 33 . Los numerosos viajeros griegos que visitaron Egipto a lo largo del tiempo podrían haber presenciado estas diferentes situaciones, de modo que alegar ahora esa estabilidad parece más una creación legendaria que una realidad física. Platón pone en boca del sacerdote una teoría propia que más bien estaría encaminada a orientar la conversación hacia la creación de un escenario análogo al dibujado para Atenas y Atlántida. La geografía del delta, su ubicación entre dos cauces, le acerca al modelo de la Atenas ideal situada entre dos ríos, pero las ingentes y grandiosas obras hidráulicas para aprovechar la crecida (y las características construcciones religiosas egipcias), también descritas por Heródoto, nos recuerdan la desmesura constructiva de los atlantes.

Situando la geografía egipcia en un escenario difuminado en su temporalidad y espacialidad, entre el mito y la física, fuera de un marco evolutivo, viene a reforzar la visión tradicional de Egipto, pero acomodándola al marco del logos platónico sobre los orígenes (como lo había hecho con el atlante y el ateniense). Lo que Platón quería de Egipto era generar un modelo de mundo político e intelectual que completara los otros dos. Las crecidas anuales eran una forma de recuperar cíclicamente la originariedad. Todos los años la naturaleza surgía otra vez en su estado inicial, no había espacio para la degeneración. Ofrecía un tipo de estabilidad geográficosocial que difería con el ideal, en el sentido de que este había tenido su existencia limitada por las catástrofes, y aún así había conseguido la justicia, y él, sin ese límite, no la había conseguido por su erróneo sentido de las relaciones entre política y religión. Si Atenas y Atlántida están construidas como dos formas contrapuestas de austeridad y exuberancia, o de autonomía y heteronomía, Egipto es una mezcla de ambas, autosuficiente, pero urbanísticamente opulenta. Ni alcanza la idealidad/degeneración atlante ni tampoco la idealidad ateniense, y es ese carácter mixto el que también configura su espacio ${ }^{34}$. Su territorio no se ve afectado por las catástrofes naturales periódicas, por lo que permanece estable en su buena disposi-

gedia (Arquelao, frag. 228 Nuck). Eudoxo, informado por sacerdotes egipcios, afirma que la inundación del Nilo es causada por las abundantes lluvias que caen en Etiopía (frag. citados en Méautis, 1919, p. 27).

33 Ver Castañeda (2003); Pérez Lagarcha (2006, pp. 40-45); Iván Bolaños (2003). Precisamente, en el mismo reinado de Amasis, momento en el que se atribuye ficticiamente a Solón un viaje a Egipto, tuvo lugar una crecida, calificada como un auténtico diluvio, como una gran maldición (M.G. Daressy, 1923).

${ }^{34}$ La Atlántida en su estadio originario era una sociedad perfecta como la Atenas ideal. En un segundo momento caerá en la degeneración por el abandono de su parte divina, de modo que gracias a la derrota militar que sufrirá a manos de los atenienses volverá a su situación original. 
ción y facilidad de explotación, pero al estar el gobierno en manos de la clase sacerdotal (aunque un poder colectivo, no está basado en la sabiduría dialéctica de los guardianes republicanos), esa potencial riqueza genera un urbanismo más próximo a la grandiosidad y a la expresión religiosa propias de la Atlántida (el poder unitario cuya estabilidad descansa en la de la personalidad de un rey filósofo). El argumento de reversión tan utilizado en estos diálogos se quiebra en Egipto. Su naturaleza no degenera, pues anualmente surge renovada. El proceso erosivo que sólo se da en Atlántida y Atenas, puede ser utilizado como elemento reversible para llegar al origen, pero en Egipto sólo podemos observar su invariable actualidad. El origen está permanentemente en el hoy.

\section{Conclusiones}

Las tres mitogeografías son escenarios que plantean desafíos ontológicos a sus habitantes. Como los espacios de expiación fedonianos, en cada uno de ellos esa cultura tiene que decidir cómo responder a su geografía. Nos encontramos con tres geografías diferentes en el marco de un medio ambiente inaugural, que todavía no ha sufrido procesos erosivos. Dos naturalezas fijas, estacionarias: la Atlántida, un medio dominado por la exuberancia e inagotabilidad de recursos, y Atenas, la justa proporción y templanza; y una estacional, Egipto, donde la naturaleza proporcionaba anualmente al hombre lo que necesitaba, y este había de esperar esa donación, de cuya estabilidad dependía su existencia. Dos modos de entender la naturaleza, como constancia (pródiga o proporcionada) o renovación.

Desde el Gorgias hasta el Timeo-Critias la geografía imaginaria hace posible pensar en la Justicia como un estado posible del alma. Facilita el paso desde la justicia hacia la Justicia, creando un puente entre la contemporaneidad y la Idea, permitiendo una continuidad contingente y reconocible. Genera un espacio que posibilita que la Idea vuelva al mundo, para poder intentar de nuevo su realización en un ciclo constante. Es el territorio dispuesto para la purificación del alma, la visualización de los males de la corporalidad, el lugar del enjuiciamiento de lo realizado en el mundo, la recompensa del justo. La Idea adquiere materias, ubicaciones, vivencias, mediante un logos comprensible, probable. El mito no es un reflejo de la verdad sino una forma de dotarla de un componente experiencial. El logos mítico genera una doble entrada subjetiva: como ficción nos atrae y nos permite una distracción evasiva y bella de lo injusto real y como anamnesis nos hace conscientes de la verdad que poseemos oculta. La geografía convierte el logos mítico en aprehensible desde una lógica física y en un medio literario épico.

Pero además en su remate timeocritiano, el medio geográfico inscribe en el sujeto un sentido-hacia, un estar-para, que no es determinante sino condicionante, ya que establece unos medios de subsistencia y unas formas de relación con la tie- 
rra/mar que deben ser leídas adecuadamente para que la relación alma/cuerpo adquiera su verdadero sentido ${ }^{35}$. Los atlantes lo habían hecho en sus orígenes y lo harán después de la derrota, cuando interpretaron la exuberancia como un medio facilitador de su idealidad (su ilimitación planteaba el reto de su uso proporcionado, racional), y lo abandonaron al imitar el aspecto cuantitativo de esa exuberancia y entender que su alma debía poseer para su completud un afán expansivo y posesivo inagotable; los atenienses lo venían haciendo desde siempre, gracias a que comprendieron que en su paisaje proporcionado y centrado, el alma podía hallar la posibilidad armónica de lo justo (su moderación proponía el reto de situarse correctamente entre sus márgenes y no romper su equilibrio); los egipcios no trasladaron la estabilidad autárquica de su geografía a su sociedad, en tanto que otorgaron el poder a lo religioso (no a lo divino), entendido como un hecho ritualizado, como un hacer continuado de cultos de apariencias, y no como fijación de una forma de ser invariable (su carácter periódico proponía el reto de mantenerse invariable en su voluntad de perfección). Platón entiende que el hombre debe actuar como un sujeto en el medio, y no como un objeto más del medio, debe crear su propia situación en ese escenario y no mimetizarse en él. La relación entre medio y sujeto debe darse como una dialéctica en la que el sujeto busque el ideal en el mundo auténtico o de las Ideas, a través de una intermediación racional (anámnēsis) y vital (el entorno del hoy), de forma que la interpretación de lo geográfico sea entendida por el ciudadano como un desafío que propone al alma un ejercicio constante de aproximaciones sucesivas en un viaje por regiones transitables.

\section{Referencias Bibliográficas}

\section{Fuentes}

Heródoto. Historia. Libros I-II. Madrid, Gredos, 1992 (trad. de Carlos Schrader). Platón. Diálogos II. Gorgias. Madrid, Gredos, 1992 (trad. de J. Calonge).

Platón. Diálogos III. Fedón. Madrid, Gredos, 1992 (trad. de C. García Gual). Platón. Diálogos VI. Timeo, Critias. Madrid, Gredos, 1992 (trad. de Fco. Lisi).

Platón. La República. Madrid, Akal, 2009 (introd., trad. y notas de Rosa Mariño, Salvador Mas y Fernando García).

Platón. Phedon. Ouvres completes. Tome IV. Paris, Les Belles Lettres, 1965 (ed. bilingüe, trad. de Léon Robin).

Platón. Timée. Critias. Paris, Flammarion, 1992 (trad. de Luc Brisson).

\footnotetext{
35 «Puesto que cuida siempre de su parte divina y tiene en buen orden al dios que habita en él, es necesario que sea sobremanera feliz. Ciertamente, para todos hay un único cuidado del conjunto; atribuir a cada parte los alimentos y movimientos que le son propios. Los pensamientos y revoluciones del universo son movimientos afines a lo divino en nosotros» (Timeo 90c).
} 


\section{Estudios}

BERNABÉ, A. (2011): Platón y el orfismo: diálogos entre religión y filosofía. Madrid, Abada.

BERnABÉ, A. y JimÉnez SAN CRISTÓBAL, A. (2001): Instrucciones para el más allá. Las laminillas órficas de oro, Madrid, Ed. Clásicas.

Casadesús Bordoy, F. (1997): "Orfeo y orfismo en Platón". Taula. Quaderns de pensament, 27-28, pp. 61-73.

Castañeda Reyes, J. C. (2003): Sociedad antigua y respuesta popular. Movimientos sociales en Egipto antiguo, México, UAM.

Daressy, M.G. (1923): "La crue du Nil de l'an XXIX d'Amasis", Annales du Service des antiquités d l'Egypte, 23, pp. 47-48 (texto traducido en Castañeda Reyes. Señoras y esclavas: el papel de la mujer en la historia social del Egipto antiguo. México, 2008, pág. 515, n. 335).

IvÁn Bolaños, J. (2003): "El valle del Nilo: de la geografía al mito", Cuadernos geográficos, Univ. Granada, 33, pp. 75-103.

FRIEDLÄNDER, P. (1989): Platón. Verdad del ser y realidad de vida. Madrid, Tecnos.

MÉAutis, G. (1919): "Eudoxe de Cnide et l'Egipte, contribution à l'ètude du syncrétisme gréco-égyptien", Revue de philologie, de littérature et d'histoire anciennes, n.s.: 43:1, pp. 21-35.

Millan LeÓN, J. (1998): Gades y las navegaciones oceánicas en la antigüedad (1000 a.C. -500 d. C.). Écija, Gráficas Sol.

Pérez lagarcha, A. (2006): Historia antigua de Egipto y del Próximo Oriente. Madrid, Akal.

Pradeau, J.F. (1997): Le monde de la politique. Sur le récit atlante de Platon, Timée (17-27) et Critias. Sankt Augustin, Academia Verlag.

ReYnard, J. (2000): "La géographie de l'Egypte selon Platon. Remarques sur un passage du Timee (21e)", Revue des études grecques, 113, vol. 1, pp. 131-146.

Tomás Morales Caturla

Universidad Nacional de Educación a Distancia

pchayauno@terra.com 